AMPLIFY YOUR IMPACT

Nicole Eva and Erin Shea, Editors

\section{We Share Great Stuff}

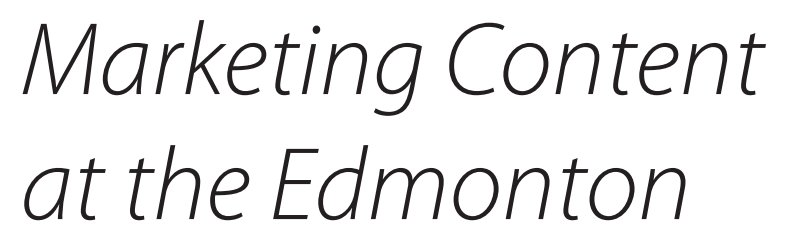
Public Library

\section{Tina Thomas}

Tina Thomas is the Director of Marketing, Communications and Fund Development at the Edmonton Public Library (EPL). She joined EPL in spring 2009 after fourteen years in the private sector. She has experience in a broad base of marketing disciplines including product and solution marketing, strategy, market analysis and business development. She holds an executive MBA from Queen's University, a Bachelor of Commerce from the University of Alberta and a Certified Public Accountant designation. Tina was the main champion and leader behind EPL's award-winning rebranding project. In 2013 she was named International Association of Business Communicators (IABC) Edmonton Communicator of the year. In 2011 she was honored as a Library Journal Mover and Shaker, as well as one of the Top 40 under 40 by Edmonton's Avenue Magazine.

Correspondence concerning this column should be directed to Nicole Eva and Erin Shea, email: nicole .eva@uleth.ca and eshea@fergusonlibrary.org.
Even though libraries don't "sell" things for money, we still want customers "buying" into us by using our materials and services. In this column, Tina Thomas shows how merchandising and following the lead of for-profit businesses has increased circulation at the Edmonton Public Library.-Editors

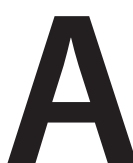
s the director of marketing at the Edmonton Public Library (EPL), I have the good fortune to work for an organization that fully embraces the value of marketing and the critical role it can play in helping ensure the success of almost any program, service, or initiative the library undertakes.

Conversations about the demise of libraries are common; so are misconceptions about what libraries do. OCLC's 2010 report on the perceptions of libraries shows people associate libraries with books-even more so than they did in previous years. ${ }^{1}$ Our content is a key part of our brand and persona and, as a result, we often think we don't need to tell people about it. In my six-year tenure at EPL I have certainly seen that the focus of most library marketing and communications efforts is on our fun and educational programs, customer service innovation, our warm and welcoming community space-and everything else we do outside of our content.

But as OCLC shows, one of-if not the main-things people love about us is that we have great stuff. How do we embrace that, showcase it, and leverage it in support of the other amazing and sometimes more glamorous work we do?

\section{HOW WE GOT HERE-ABUNDANCE, POPULARITY, DISCOVERY AND HABIT}

EPL's approach to promoting our "great stuff" has taken shape over the past several years, and has been influenced along the way by several thought leaders inside and outside the library world.

While the approach to marketing our content was in formulation well before we had the chance to view his talk, one of the key influencers-or at least points of validation that we were going in the right direction-was David Lankes, professor and Dean's Scholar for New Librarianship at the Syracuse University iSchool. In his talk "The Bad, The Good and The Great," Lankes provides some insightful views about when, where, and how libraries provide value. ${ }^{2}$ His talk proposes that the challenge people have is not scarcity of information; that the problem is not finding five hundred different descriptions of a book or reviews of a restaurant to 
try out or product to purchase. The problem is people can find five hundred when they only need two. Consumers of information today need help narrowing down and making the "right" choice. They need help sifting through the mass quantities of information available to find what best fits their interests and needs. Our recommendation, our expert opinion, our ability to narrow the choice has power.

Similarly, author, entrepreneur, and marketing guru Seth Godin has two great blog posts that speak directly to the value of libraries and the expertise of the staff who work there.

The first outlines the problem with hit radio. When we only listen to top 40 radio, we are letting the "crowd" decide what we hear. The nature of search engine optimization is to mine the Internet and find the most popular,
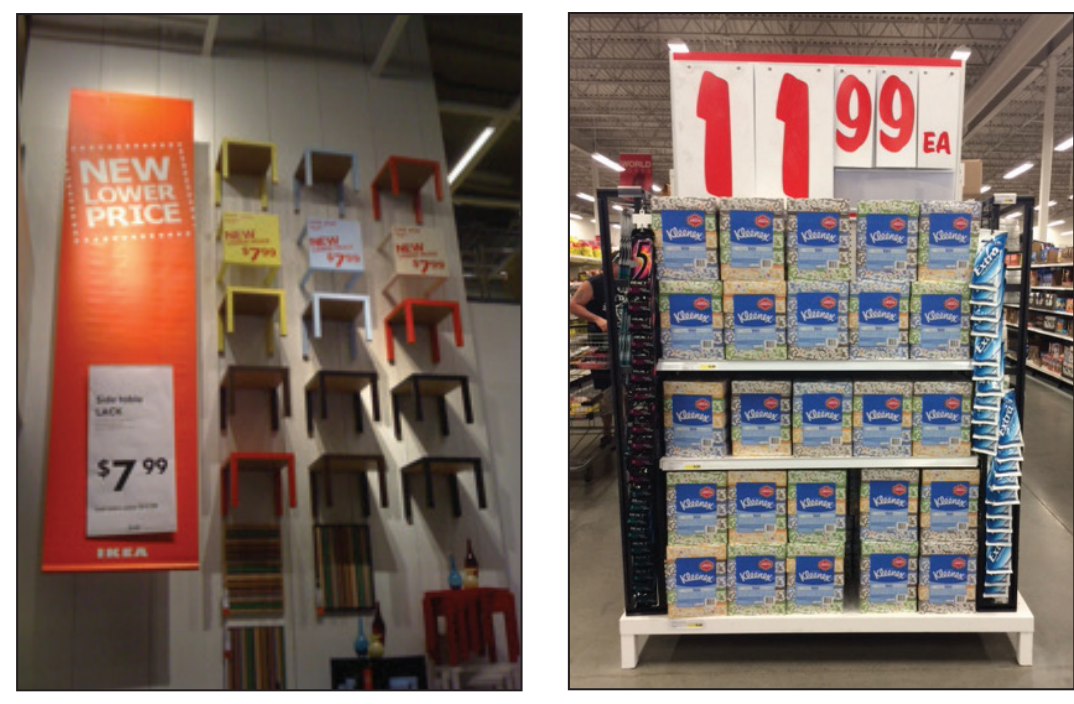

Figure 1. Retail End Cap Displays

paid for, and search-optimized content, and push it to us. As a result we keep seeing "the hits" over and over. ${ }^{3}$ As Lankes said, and we all know, information is proliferating - there are so many highly focused, niche, targeted, personalized, and great choices out there. However, by narrowing the choice to JUST what's "popular" we are giving up responsibility for our choices and what we consume to the mass opinion. Often what we consume has little to do with whether it is right for us and is more because it is popular and all we see. As Godin accurately shares, "It takes a conscious effort to seek out the thing that's a little less obvious, the choice that's a little more risky. Popular is not the same as important, or often, not the same as good." As libraries and library staff we have the chance to help people find what is a little less obvious, something more specific and likely something better and more targeted to consumers, and their specific interests, needs, or taste.

Godin has another relevant post outlining the difference between search and discovery. Search is knowing exactly what you want and trying to find it. "Discovery, on the other hand, is what happens when the universe (or an organization, or a friend) helps you encounter something you didn't even know you were looking for."4

If search is the end game, Google wins. Considering again Lankes' proposition on the value of libraries, what's missing is taking the vast amounts of information available and narrowing the choice-helping people discover ideas, new thoughts, hidden gems, options, and opportunities they didn't know were available to them. Godin poses the question "Are you working to help your customers and colleagues find what they already know what they want? Or teaching and encouraging them to find something they didn't know they needed?" As libraries, this is the opportunity in front of us.

Finally, evidence-based research from the retail sector provided the last piece to influence our approach to marketing content. I had the chance to attend international retail conference Global Shop in Chicago in 2013. One of the excellent sessions I attended was led by Herb Sorensonalso known as the Shopper Scientist (www.herbsorensen .com)_outlining how people shop. Sorenson shared that contrary to popular belief, while surprising and delighting people sounds great as a goal in the retail sector, most shoppers are driven by the desire to minimize frustration and make purchasing easy.

Why do you think retailers make displays like the two shown in figure 1 ?

According to Sorenson and his retail behavior research, habit is the servant of convenience-if you make it convenient for someone to buy something, they will, and they will buy more of it. Displays tell people what to consume. Often they don't care what it is they are choosing-they'll buy it because it's on display, which means someone with some knowledge or opinion has recommended it. As Lankes notes, someone has narrowed the choice. For most retail stores 20-50 percent of sales come from end cap displays. Retailers make displays and narrow choice because it is a good business decision-it increases sales and not just for what's on display; everything sells better when there are displays.

\section{STAFF PICKS-HIGHLIGHTING THE FRESH, QUIRKY, AND FUN}

So what did all these somewhat disparate but interconnected thoughts help influence at EPL? In 2013 we implemented a completely new approach to customer service and advisory services-Discovery Services.

Discovery Services brings together all the elements of customer engagement and experience including information services, readers' advisory, reference, digital literacy instruction, and customer service under one umbrella. Why? Because we recognized customers don't group their questions into discreet categories like readers' advisory or tech help, 


\section{AMPLIFY YOUR IMPACT}

so why should we? Every single customer engagement is an opportunity to showcase our services, make a recommendation, sign someone up for a program, or advocate for EPL.

One of the outcomes of our Discovery Services model specifically related to marketing our content was a focus on Staff Picks-on using our expert opinions to help narrow the choices and showcase great content and staff expertise to our customers. Unlike previous attempts at creating materials to showcase our recommendations, we leveraged our brand to help create and implement a common approach and consistent look and feel.

To highlight our staff expertise Staff Picks are shared under the banner "we read, we listen, we watch, we game and we share." We are smart, interesting, diverse, and opinionated. We know great content, and we can help our customers find it.

Building on Sorenson's ideas around the importance of displays, we developed common marketing pieces replicated in print, in branch, and online. In branch we have large display signage, bookmarks, and personalized stickers as a way to quickly and easily identify Staff Picks. We showcase our Staff Picks as part of a common displayer in a high traffic portion of our branch. This allows customers to browse staff recommendations and even follow individuals who consistently provide recommendations they like.

This model allows our staff to showcase their own personal interests and tastes. For example, Angelica is a new mom so her personal information consumption tends towards anything related to babies. She leveraged the marketing tools available to her putting a sticker on her Staff Pick choice. She took it a step further placing a Staff Picks bookmark with a personalized message at a chapter she found particularly relevant.

Additionally, if she sees a person browsing or signing out one of her picks, she introduces herself and starts a conversation about the item the customer is looking at. As Angelica notes "It's

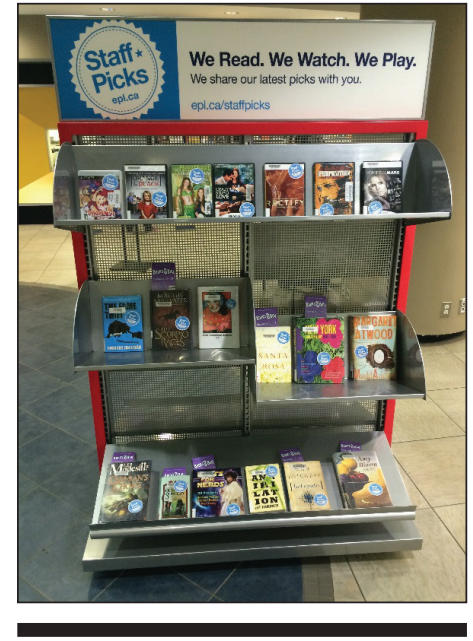

Figure 2. Staff Picks Display an easy way to become a 'real person' to our customers."

Staff Picks was introduced at Angelica's branch as a fun thing for staff to do while on the floor, not just another task to complete. Staff have challenged each other to keep the display filled. They play games like "whose book will go first?" or they put out a book and then keep track of when it is checked out.

A key part of our approach is reducing fear and encouraging staff they can do it. While some staff certainly have

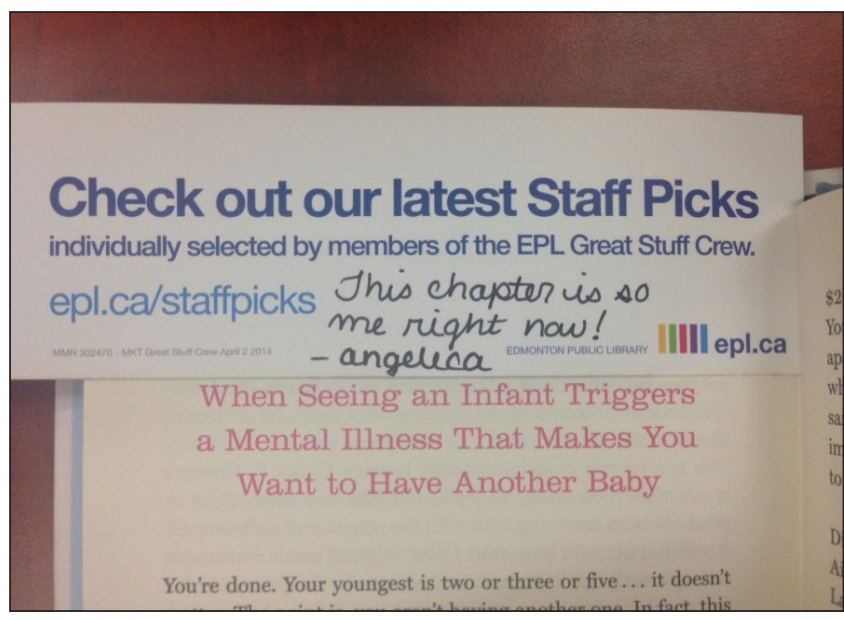

Figure 3. Personalized Staff Pick Book Mark

more skill and professional expertise to support making educated, timely, and relevant recommendations, we all can participate. At the branch where Angelica works, all staff, including students, are encouraged to make recommendations and help keep the Staff Picks display full. Carolyn, in our purchasing division, is a huge reader of adult fiction and has some great suggestions. I am not a librarian but listen to audiobooks on my commute to work each day and feel very comfortable sharing my latest find. Vanessa was an administrative professional on my team but she had a special interest in zombies, $\mathrm{HBO}$, and science fiction. She made some of our most interesting, well-thought, and timely recommendations. We can all participate at different levels.

We put together best practices to help guide staff on how best to make recommendations, but the top philosophy is to have and be fun. Our content is interesting and diverse. Charm, wit, and personality displayed through our recommendations best reflects who we are-smart, engaged, and passionate people. It also entices customers to take our recommendations and keep coming back for more.

\section{MERCHANDISING-CONSISTENT TOOLS TO HELP NARROW THE CHOICE}

For the past couple years EPL has been expanding our understanding and use of merchandising tools and practices.

We know merchandising and displays work based on the work of Sorenson and other retail experts have done. But some displays work better than others. We are all "shoppers." We know what we expect when we are customers outside the library. We know what is inviting and enticing. Clip art, construction paper, tattered, torn, and faded, is not.

If we want our staff to create displays that best reflect our brand-showcasing the image, personality, and identity we want to present to our customers-we need to make it easy for them to display our content in ways that create interest and resonate with our customers. To help staff and increase 

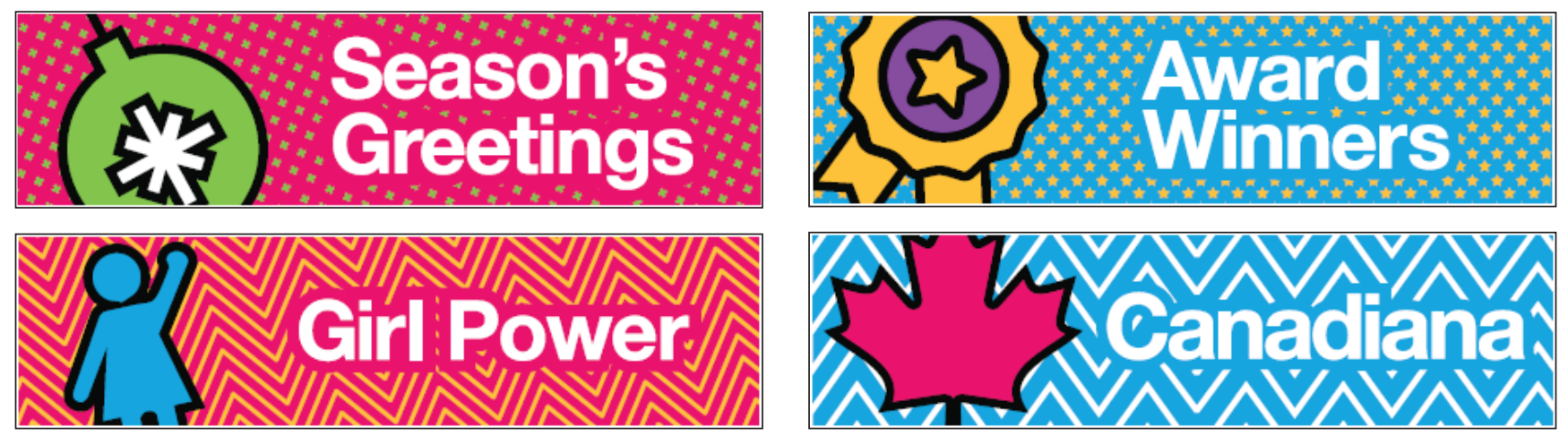

Figure 4. Display Theme Design Samples

our visual merchandising we established a small team two years ago with the mandate to create common merchandising tools, guidelines, and practices across EPL.

With nineteen locations of all different shapes and sizes across our city, a critical component of our approach to merchandising was creating common display themes, aligned to our brand, that branches could use in their displays. We surveyed branch staff to get ideas and feedback on the most popular, relevant, and needed themes, and then we developed a design system that would ensure they looked and felt like they all belonged together.

Figure 4 shows a sampling of the approximately twenty themes we designed. We built versions of the artwork to allow them to be used in different orientations. We wanted to create flexibility so concepts could be used in multiple ways. For example, themes like "all you need is love" or "spooktacular" allow the display materials to be used around holiday events but also allow provide the opportunity to be used at other times of the year.

Part of the reason staff had a hard time making displays is they didn't have the right tools to create them, so our next step was to implement standardized furniture and equipment across our system. We purchased a double-sided, freestanding displayer for each of our locations shown in figure 2 and again in figure 5. An oversized sign showcases our merchandising themes and allows the look of the display to change as the topic does. Similarly, to support the creation of table top displays, we implemented simple plexiglass sign holders in standard sizes as shown in figure 6.

We also recognized the importance of creating display opportunities throughout each branch. To meet this need we added shelf-end displays to our new system-wide signage and wayfinding standards, providing dedicated display space close to the content home. We also modelled an inaisle displayer, shown in figure 7 after we saw a similar approach at King County Library System. The oversized poster holder allows us to draw people in using the same themes developed for the freestanding and tabletop displayers but in a different orientation.

The final piece in our tool kit is shelf blocks. Retail book stores have the benefit of multiple copies of an item which

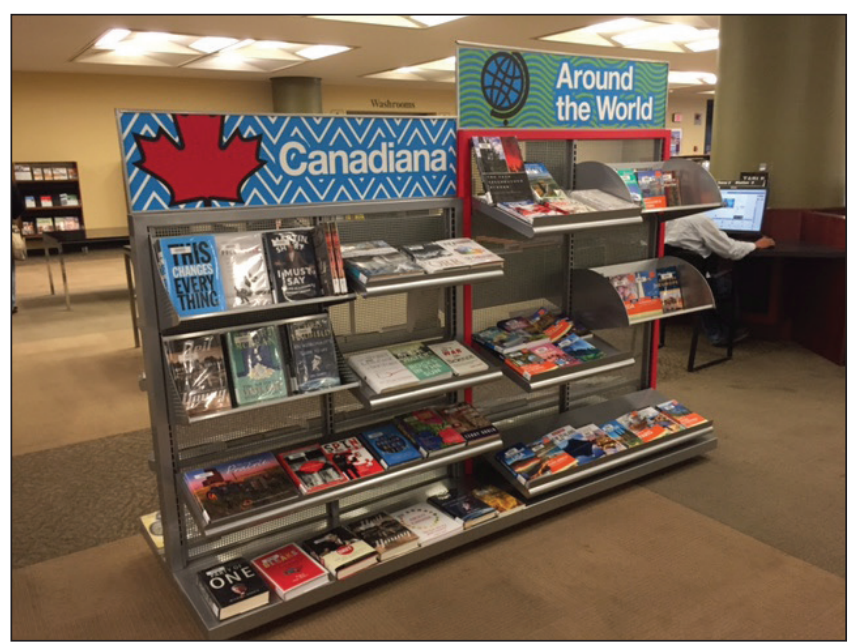

Figure 5. Freestanding Displayer

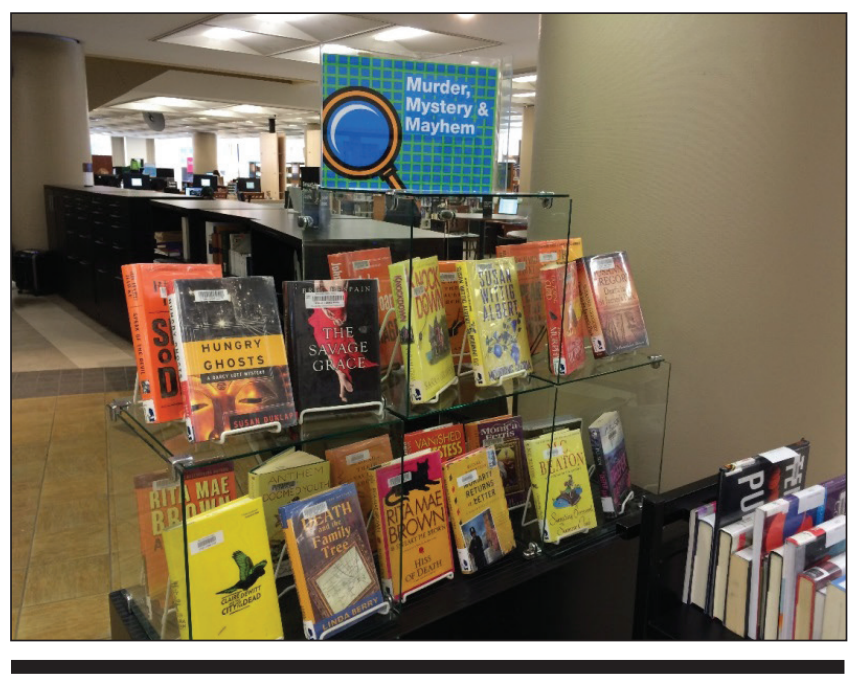

Figure 6. Tabletop Display

allows them to face material outwards-better showcasing the content by allowing customers to see the cover. Libraries don't always have the same ability because we often don't have the same volume of copies of any single item. Tools can help us. 


\section{AMPLIFY YOUR IMPACT}

Figure 8 shows our implementation and use of custom-designed shelf blocks that sit behind a book and allow it to face out. Tools similar to this already exist-and we tried them. Unfortunately the plexiglass material broke easily. In fact almost 15 percent of what we ordered as a trial was broken in the box when it arrived. In addition, the angled front face and bottom lip did not best

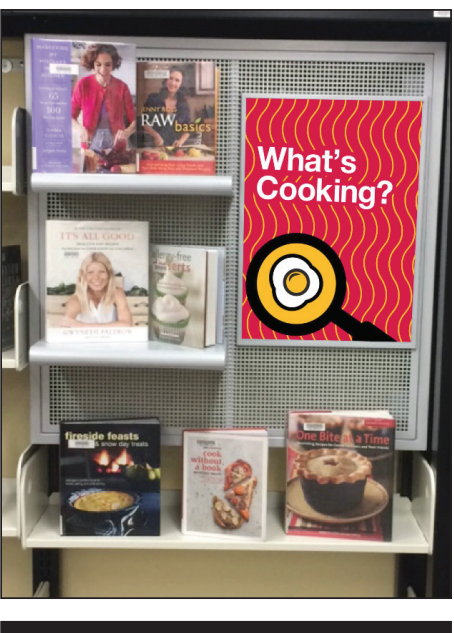

Figure 7. In-Aisle Displayer showcase the content on display. Rather than purchase on an off-the-shelf product, we designed a custom piece with a more durable and flexible material. The depth of the shelf block ensures only one or two items need to be in front to achieve the look of front-facing content display.

There is also a space to insert marketing materials as shown in figure 9. While the space could be used to promote upcoming EPL programs and services, we kept the messages higher level and aligned to our brand value statement so the system is easier to manage and maintain. With this approach materials can be displayed front-facing in aisle, encouraging customers to look at them and pick them up. Then when the item is taken the presentation still looks good.

\section{WHERE WE'RE HEADED-MARKETING OUR CONTENT IS AN ONGOING PRIORITY}

EPL is committed to helping our customers find great stuff by leveraging our staff expertise and personality, as well as through the use of tools that make it easy for our customers to discover something new. Staff Picks and merchandising tools are just two of the pieces we've implemented to increase our ability to share our great content.

In 2013 we developed a signage and wayfinding strategy for all nineteen of our locations to help ensure customers could navigate any of our locations quickly and easily. We are 80 percent of the way through implementing this strategy. Over the past two years we've also dedicated significant marketing efforts to promoting our digital content, leveraging various channels such as in branch, social media, website, earned media, and advertising. The results have been stellar and we'll continue to use the abundance of popular, diverse and interesting content to bring customers to the library.

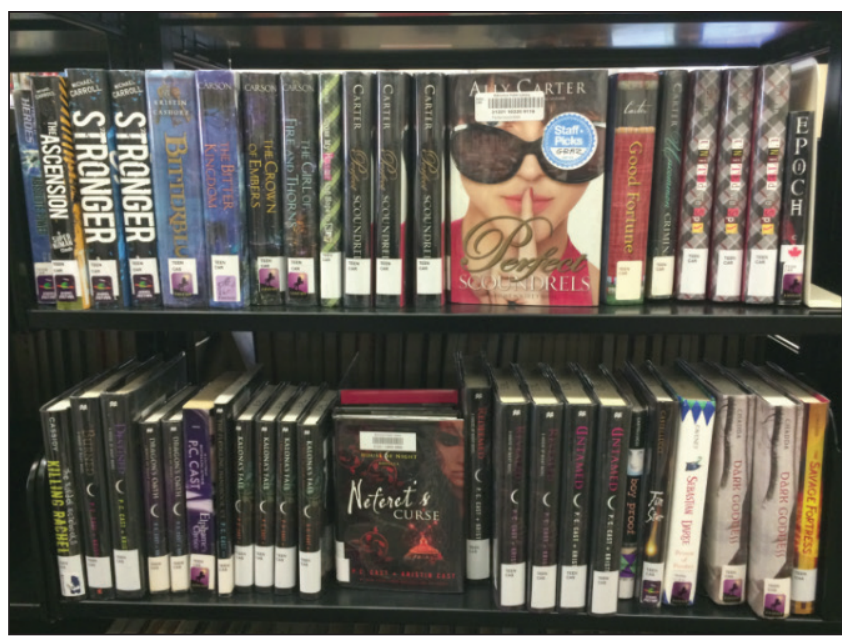

Figure 8. In-Aisle Display Block with Materials in Front

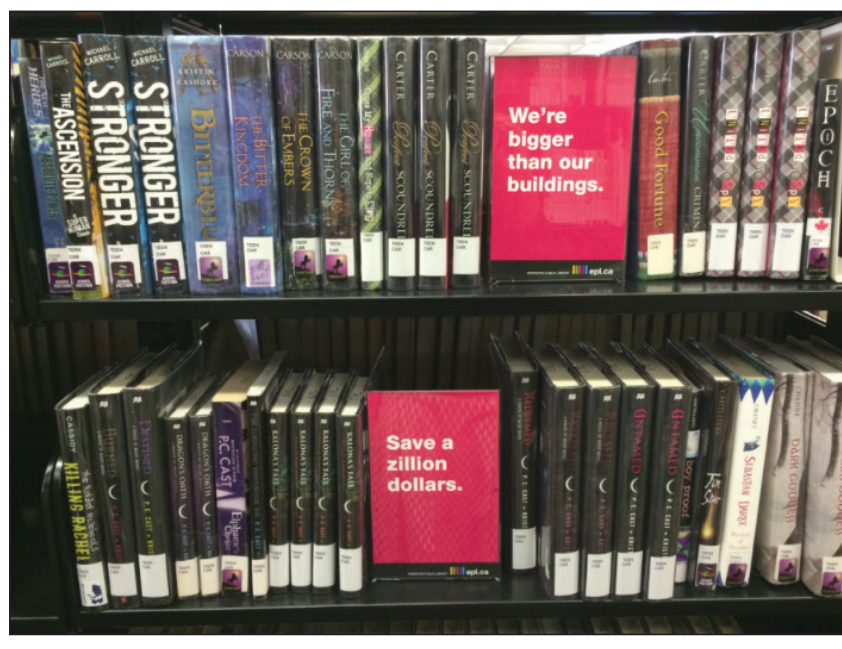

Figure 9. In-Aisle Display Block without Materials in Front

Overall, the direction is clear. We have great stuff and we are committed to sharing it with our customers. We're putting the systems, practices and tools in place to make it happen.

\section{References}

1. OCLC, OCLC Perceptions of Libraries 2010: Context and Community (Dublin, OH: OCLC, 2011), 38, www.oclc.org/content/dam/ oclc/reports/2010perceptions/2010perceptions_all.pdf.

2. R. David Lankes, Professor and Dean's Scholar for New Librarianship Syracuse University iSchool, "The Bad, The Good and The Great," http://vimeo.com/84272541.

3. Seth Godin, "The Problem with Hit Radio," This is Seth's Blog, May 28, 2014. http://sethgodin.typepad.com/seths_blog/2014/05/ the-problem-with-hit-radio.html.

4. Seth Godin, "Search vs Discovery," This is Seth's Blog, April 5, 2014, http://sethgodin.typepad.com/seths_blog/2014/04/ search-vs-discovery.html. 